\title{
Differences in zinc status and the leptin axis in anorexic and recovered adolescents and young adults: a pilot
} study

\author{
F.D. Zepf $f^{1,2,3 *}$, I. Sungurtekin ${ }^{4}$, F. Glass ${ }^{5}$, L. Elstrodt ${ }^{5}$, D. Peetz ${ }^{6,7}$, \\ G. Hintereder ${ }^{8}$, J. Kratzsch ${ }^{9}$, C.S. Biskup ${ }^{1,3}$, F. Poustka ${ }^{5}$ and \\ L. Wöckel ${ }^{1,5,10}$
}

'Department of Child and Adolescent Psychiatry, Psychosomatics and Psychotherapy, RWTH Aachen University, Aachen, Germany; ${ }^{2}$ Institute for Neuroscience and Medicine, Jülich Research Centre, Jülich, Germany; ${ }^{3}$ JARA Translational Brain Medicine, Aachen, Germany; ${ }^{4}$ Department of Child and Adolescent Psychiatry and Psychotherapy, Central Institute of Mental Health, Mannheim, Germany; ${ }^{5}$ Department of Child and Adolescent Psychiatry, Psychosomatics and Psychotherapy, J.W. Goethe University, Frankfurt am Main, Germany; ${ }^{6}$ Institute of Laboratory Medicine, HELIOS Klinikum Berlin-Buch, Berlin, Germany; ${ }^{7}$ Department of Clinical Chemistry and Laboratory Medicine, University Center of Johannes Gutenberg University, Mainz, Germany; ${ }^{8}$ Department of Laboratory Medicine, J.W. Goethe University, Frankfurt am Main, Germany; ${ }^{9}$ Institute of Laboratory Medicine, Clinical Chemistry and Molecular Diagnostics, University of Leipzig, Leipzig, Germany; ${ }^{10}$ Center of Child and Adolescent Psychiatry and Psychotherapy, Clienia Littenheid AG, Littenheid, Switzerland

Abstract

Background: Evidence from animal studies suggests that leptin metabolism is associated with zinc (Zn) status. However, research investigating this relationship in adolescents and young adults with anorexia nervosa (AN) is scarce; the present study aims to fill that gap.

Methods: Serum concentrations of leptin, the soluble leptin receptor (sOB-R) and the free leptin index (FLI) were obtained in healthy control subjects $(n=19)$, acutely ill individuals $(n=14)$ and recovered patients with $\mathrm{AN}(n=15)$. Serum $\mathrm{Zn}$ concentrations noted in previous research data were also incorporated for all groups. Results: Leptin, FLI and Zn concentrations were higher in recovered subjects with AN when compared with acutely ill AN patients. Remitted patients showed higher sOB-R concentrations but no difference in FLI compared with the control group. Leptin and FLI were lower in the acutely ill patients compared with the control subjects, who showed no differences in $\mathrm{Zn}$ concentrations. Zn concentrations were not correlated with leptin, sOB-R or FLI concentrations in any of the three investigated subgroups.

Conclusions: The present investigation does not entirely support an association between $\mathrm{Zn}$, Leptin and FLI concentrations in subjects with AN, possibly due to limited statistical power. Further research and replication of the present findings related to the interaction between leptin and $\mathrm{Zn}$ is warranted. However, with respect to serum leptin levels the data of the present investigation indicate that acutely ill and remitted patients with AN differ as regards serum leptin concentrations and FLI, which is in line with previous research.

Keywords: anorexia nervosa; leptin; leptin receptor (sOB-R); free leptin index (FLI); zinc

Received: 18 October 201।; Revised: 21 December 20II; Accepted: 5 January 20 I2; Published: I March 2012

$\mathrm{P}$ ast research has indicated that the hormone leptin is a major player when it comes to triggering the adaption of the human body to severely restricted food intake (1-3). Studies focusing on the regulation of leptin levels during a zinc $(\mathrm{Zn})$ deficiency showed that circulating leptin concentrations are diminished during
Zn deficiency in rats and humans $(4,5)$. There seem to be two mechanisms responsible for this phenomenon: a decrease in the amount of leptin produced per gram of adipose tissue (6), and an overall reduction in body fat during $\mathrm{Zn}$ deficiency (7). With respect to previous findings, marginal $\mathrm{Zn}$ deficiency in rats decreased leptin 
expression independently of food intake, while decreasing corticotrophin-releasing hormone in relation to food intake (8), suggesting that leptin expression may be directly affected by $\mathrm{Zn}$. Further research suggests that decreased food intake, rather than $\mathrm{Zn}$ deficiency itself, is associated with changes in plasma leptin, metabolic rate and activity levels in $\mathrm{Zn}$ deficient rats; thus, it seems that low serum leptin concentrations, hypometabolism, and decreased activity are more likely the result of anorexia than of $\mathrm{Zn}$ deficiency per se $(9,10)$. However, data investigating this relationship in adolescent humans and young adults with anorexia nervosa (AN) do not exist.

Research has indicated that the free leptin index (FLI) is a valuable tool for investigating the leptin axis during growth and sexual maturation (11). FLI is calculated using the ratio of leptin to the soluble leptin receptor (sOB-R). In human blood, leptin is bound by a highaffinity binding protein; this particular protein appears to be identical to the sOB-R. We previously reported differences in serum $\mathrm{Zn}$ concentrations between remitted and acutely ill patients with AN (12), with elevated serum $\mathrm{Zn}$ concentrations in remitted patients. This difference was most likely linked to reported dietary preferences, in particular as regards $\mathrm{Ca}^{2+}$ and phosphorus containing foods which can influence absorption of $\mathrm{Zn}$.

$\mathrm{Ca}^{2+}$ and phosphate can decrease $\mathrm{Zn}$ absorption, and previous findings in this sample demonstrated that acutely ill patients had higher serum $\mathrm{Ca}^{2+}$ and inorganic phosphate concentrations when compared to controls, and also preferred foods containing $\mathrm{Ca}^{2+}$ and phosphorus (12).

In view of the expected correlation between altered serum leptin levels and $\mathrm{Zn}$ metabolism, we aimed to investigate potential interactions between $\mathrm{Zn}$ status and the leptin axis in acutely ill and remitted AN patients in comparison with healthy controls. The data on $\mathrm{Zn}$ concentrations referred to in this paper are published separately (12). In line with previous research, we hypothesised that acutely ill patients would present with lower serum leptin concentrations when compared with remitted patients. We also expected that altered serum leptin levels would be correlated with $\mathrm{Zn}$ concentrations $(4,5)$, in particular in the group of acutely ill patients.

\section{Methods}

\section{Study sample}

Forty-eight participants were enrolled in the study (for characteristics see Table 1). The study sample and the respective subgroups are identical to those used in previous research studies (12). The present work focuses on the interaction of serum $\mathrm{Zn}$ concentrations with leptin, sOB-R and FLI.

Acutely ill patients $(n=14)$ met weight and diagnostic criteria for AN (ICD-10, BMI $<10$ th percentile or
$\mathrm{BMI}<17.5$, with a mean duration of illness of $6.1 \pm 3.7$ years). All subjects were administered the Structured Interview for Anorexia and Bulimia Nervosa (SIAB) (13-15) and the Eating Disorders Inventory Symptom Checklist (EDI-SC) (16). Secondary school students, medical students and associated staff of a major mental health service served as a control group $(n=15)$; they did not display eating disorder symptoms and had normal menses (12). Other co-morbid psychiatric disorders were ruled out using clinical interviews. The remitted patients $(n=19)$ were sent letters inviting them to participate in the study. A BMI of at least 18 was required for the group of remitted patients; all remitted subjects were symptom-free based on the SIAB. Moreover, recovered patients needed to have maintained a normal weight for at least 1 year prior (mean period of recovery $6.0 \pm 2.7$ years) without vomiting, binging, or irregular menses (mean duration of regular menstruation after amenorrhea during acute illness: $6.3 \pm 3.3$ years; mean duration of amenorrhea during acute illness: $11.2 \pm$ 10.5 months (12). Participants in the remitted group with abnormal blood chemistry (e.g. serum thyroid hormones, liver enzymes and electrolytes) were not included in the analysis. Previous and current medical diseases were ruled out using patient history, and acute as well as recent infections met exclusion criteria for participation. Data on the intake of dietary supplements as well as medications are provided in a different publication (12). Subjects who took oral contraceptives did not differ from subjects who did not in regard to serum $\mathrm{Zn}$ concentrations (12), which was examined because the intake of oral contraceptives has been associated with lower $\mathrm{Zn}$ concentrations $(17,18)$. The study protocol was assessed and approved by the Ethics Committee of the Faculty of Medicine at J.W. Goethe University, Frankfurt am Main, Germany. The investigation was carried out in accordance with the Declaration of Helsinki.

\section{Assessment}

Blood samples from the healthy control group and the remitted group were obtained during a single visit at the above-mentioned mental health service (in addition, assessment of weight, height, BMI, SIAB and EDI-SC took place). Blood samples for the assessment of $\mathrm{Zn}$ status in acutely ill patients were obtained following admission. Trace mineral-free plastic tubes containing $2 \%$ sodium oxalate were used for blood sampling. The obtained blood samples were then placed on ice. An atomic absorption spectrophotometer (PerkinElmer, Germany; intra-assay imprecision was between 2.7 and $3.2 \%$, inter-assay imprecision was between 4.3 and $5.3 \%$ ) was used to determine serum $\mathrm{Zn}$ concentrations (Johannes Gutenberg-University) (12). Other routine laboratory tests (e.g. electrolytes, liver enzymes) were 
Table 1. Characteristics of the control group $(n=15)$, acutely ill patients with anorexia nervosa (AN, $n=14)$ and remitted patients with AN $(n=19)$

\begin{tabular}{|c|c|c|c|c|c|c|c|c|c|c|c|c|}
\hline & \multicolumn{3}{|c|}{$\begin{array}{l}\text { Healthy control } \\
\text { subjects }(n=15)\end{array}$} & \multicolumn{3}{|c|}{$\begin{array}{l}\text { Acutely ill patients } \\
\text { with AN }(n=14)\end{array}$} & \multicolumn{3}{|c|}{$\begin{array}{l}\text { Remitted patients } \\
\text { with AN }(n=19)\end{array}$} & \multirow{2}{*}{$\begin{array}{c}\begin{array}{c}\text { Controls vs. } \\
\text { acutely ill } \\
\text { patients }\end{array} \\
P_{1}\end{array}$} & \multirow{2}{*}{$\begin{array}{c}\begin{array}{c}\text { Controls vs. } \\
\text { remitted } \\
\text { patients }\end{array} \\
P_{2}\end{array}$} & \multirow{2}{*}{$\begin{array}{c}\text { Acutely ill } \\
\text { vs. remitted } \\
\text { patients } \\
p_{3}\end{array}$} \\
\hline & $M \pm S D$ & Min. & Max. & $M \pm S D$ & Min. & Max. & $M \pm S D$ & Min. & Max. & & & \\
\hline Age (years) & $24.80 \pm 2.78$ & 20.42 & 29.91 & $20.75 \pm 4.7 \mid$ & 14.58 & 29.50 & $24.24 \pm 3.31$ & 17.42 & 29.91 & 0.008 & ns & 0.018 \\
\hline Weight (kg) & $59.06 \pm 6.18$ & 50.00 & 71.30 & $45.92 \pm 6.14$ & 39.00 & 58.9 & $58.22 \pm 6.00$ & 50.10 & 70.80 & 0.000 & ns & 0.000 \\
\hline Height (cm) & $167.43 \pm 5.60$ & 158 & 176 & $166.63 \pm 6.95$ & 157 & 181 & $165.53 \pm 5.4$ & 158 & 177 & ns & ns & ns \\
\hline BMI $\left(\mathrm{kg} / \mathrm{m}^{2}\right)$ & $21.06 \pm 2.02$ & 17.81 & 24.98 & $16.45 \pm 1.26$ & 13.68 & 16.45 & $21.13 \pm 1.86$ & 18.18 & 24.50 & 0.000 & ns & 0.000 \\
\hline Zinc ( $\mu g / d l)$ & $59.95 \pm 11.25$ & 33.40 & 77.80 & $62.23 \pm 13.78$ & 40.30 & 89.50 & $81.75 \pm 16.2$ & 52.67 & 114 & ns & 0.000 & 0.001 \\
\hline Leptin (ng/ml) & $10.10 \pm 6.42$ & 0.03 & 25.9 & $4.53 \pm 5.8$ & 0.001 & 23.4 & $11.92 \pm 7.37$ & 2.77 & 27.30 & $0.021^{* *}$ & ns & $0.004^{*}$ \\
\hline sOB-R (ng/ml) & $18.94 \pm 5.77$ & 9.0 & 28.6 & $21.30 \pm 6.77$ & 13.4 & 34.4 & $24.79 \pm 9.81$ & 12.8 & 47.5 & ns & $0.05 I^{* *}$ & ns \\
\hline $\mathrm{FLI}$ & $60.8 \times 10^{3} \pm 48.6 \times 10^{3}$ & $0.1 \times 10^{3} 74.70$ & $159.6 \times 10^{3}$ & $24.6 \times 10^{3} \pm 35.0 \times 10^{3}$ & $0.005 \times 10^{3}$ & $141.8 \times 10^{3}$ & $54.3 \times 10^{3} \pm 36.0 \times 10^{3}$ & ${ }^{3} 13.6 \times 10^{3}$ & ${ }^{3} 128.8 \times 10^{3}$ & $0.03 I^{* *}$ & ns & $0.027^{* *}$ \\
\hline
\end{tabular}

Data are presented with mean (M), minimum (Min.), maximum (Max.), and standard deviation (SD). Mean values were compared ( $t$-tests, two-tailed) for significant differences between controls and acutely ill patients with AN $\left(p_{1}\right)$, controls and remitted patients with $\mathrm{AN}\left(p_{2}\right)$ and acutely ill patients with AN versus remitted patients with $\mathrm{AN}\left(p_{3}\right)$.

sOB-R - soluble leptin receptor; FLI - free leptin index.

*Excellent power (0.99); **moderate power (0.8-0.9). 
performed at the Department of Laboratory Medicine at J.W. Goethe University in Frankfurt am Main.

\section{Leptin}

Leptin was measured by an in-house RIA $(11,19)$, with intra-assay and inter-assay coefficients of variation lower than $12.5 \%$ (range: 1 and $8 \mathrm{ng} / \mathrm{ml}$ ). Recovery of dilution experiments (undiluted to $1: 20$ ) was $88-112 \%$ for the concentration range between 4 and $6 \mathrm{ng} / \mathrm{ml}$. Leptin levels of the in-house RIA were comparable with the levels of commercially available leptin RIA (Mediagnost, Tuebingen, Germany) in the sera of normal-weight and obese subjects.

\section{sOB-R and FLI}

Concentrations were determined by an in-house ligandimmunofunctional assay (11). Briefly, microtiter plates with anti-sOB-R IgG coated wells were used, with the anti-sOB-R IgG having been raised in rabbits against recombinant sOB-R ( $\mathrm{R} \& \mathrm{D}$, Wiesbaden, Germany). Incubation with PBS, 1\% bovine serum albumin for $1 \mathrm{~h}$ at room temperature was performed in order to block potentially unspecific binding sites. Either rsOB-R standards $(10 \mu \mathrm{l})$, ranging from 6.25 and $100 \mathrm{ng} / \mathrm{ml}$, or the serum samples were added to the wells. The rsOB-R standards were incubated overnight at $4{ }^{\circ} \mathrm{C}$ with an excess of biotinylated leptin in assay buffer ( $1 \%$ rabbit globulin, $0.1 \%$ BSA and $0.05 \%$ Tween 20 in PBS). An established recombinant $\mathrm{SOB}-\mathrm{R}$ preparation was used for calibration purposes $(11,20)$. A parallel course between rsOB-R and native sOB-R was found. Europium-labeled streptavidin (PerkinElmer, Germany) was used to detect the complex of biotinylated leptin and sOB-R. The plate was washed with PBS $(0.05 \%$ Tween 20$)$ each time between coating, blocking, incubation and detection. The Victor-system (PerkinElmer, Germany) was used to measure the solid phase-linked fluorescence signal of Europium. The resulting signal was dependent on both immunological recognition of the $\mathrm{SOB}-\mathrm{R}$ and leptin binding. Intra-assay and inter-assay coefficients of variation for two of the control samples were lower than $11.7 \%$. As was shown previously, the assay used was nearly insensitive to the interference of leptin (11).

The free leptin index (FLI) was determined by calculating the ratio of the levels of leptin to sOB-R, multiplied by 100 .

$\mathrm{Zn}$

As reported previously, trace mineral-free plastic tubes containing $2 \%$ sodium oxalate were used to collect blood samples and then placed on ice (12). An atomic absorption spectrophotometer (PerkinElmer, Germany) was used to assess serum $\mathrm{Zn}$ concentrations.

\section{Data analysis}

The PASW Statistics 18 software package (SPSS, Chicago, USA) was used for data analysis. Serum leptin concentrations, sOB-R and FLI were normally distributed (Kolmogorov-Smirnov goodness of fit test). Statistical significance was assumed for $p<0.05$. $t$-tests (two-tailed) were implemented for between-group comparisons. Pearson correlations (two-tailed) were used for additional dimensional analyses in regard to correlations between $\mathrm{Zn}$ concentrations and leptin, sOB-R and FLI in the different subgroups. Because of the explorative nature of this investigation, significant $p$-values were not subjected to alpha-adjustment to avoid overlooking potential effects and interactions. The data on $\mathrm{Zn}$ concentrations had been previously subjected to alpha-adjustment (12) in accordance with the Bonferroni-Holm procedure (21). Adjusted $p$-values in regard to $\mathrm{Zn}$ concentrations are indicated by $p_{\text {adj. }}$.

\section{Results}

\section{Comparison of subgroups}

Acutely ill versus remitted

Serum leptin concentrations $(t=-3.108, \quad F=4.338$, $p=0.004$, df $=1,31)$ and FLI $(t=-2.329, F=1.578$, $p=0.027, \mathrm{df}=1,30)$ were higher in remitted subjects compared with acutely ill patients, but there were no differences in sOB-R concentrations between those two subgroups (see Table 1, Fig. 1a-c). As previously mentioned, remitted $\mathrm{AN}$ patients with had significantly higher serum $\mathrm{Zn}$ levels compared with the acutely ill AN patients $\left(t=-3.642, F=0.522, p_{\text {adj }}=0.002\right.$, df $=1,31$; see Fig. $1 \mathrm{~d}$ and (12)).

Remitted versus controls

There was nearly a statistically significant difference in sOB-R concentrations $(t=-2.031, \quad F=4.565, p=$ 0.051 , df $=1,31)$, with remitted patients showing higher sOB-R concentrations (see Fig. 1b). There were no differences in FLI concentrations between controls and remitted patients $(t=0.440, F=0.906, p>0.05$, df $=$ 1,31; see also Fig. 1c). Remitted AN patients had significantly higher $\mathrm{Zn}$ levels than the control subjects $\left(t=-4.435, \quad F=2.427, \quad p_{\text {adj }}=0.000, \quad \mathrm{df}=1,32 ; \quad\right.$ see Fig. 1d and (12)).

\section{Acutely ill versus controls}

As shown in Fig. 1a and c, serum leptin concentrations $(t=2.447, F=1.310, p=0.021, \mathrm{df}=1,27)$ and FLI were higher in control subjects compared with acutely ill AN patients $(t=2.276, \quad F=2.905, \quad p=0.031, \quad \mathrm{df}=1,27)$. There was no significant difference in $\mathrm{Zn}$ serum levels between acutely ill patients and controls $(t=-0.490$, $F=0.644, p>0.05$, df $=1,27$; see Fig. $1 \mathrm{~d}$ and (12)). 

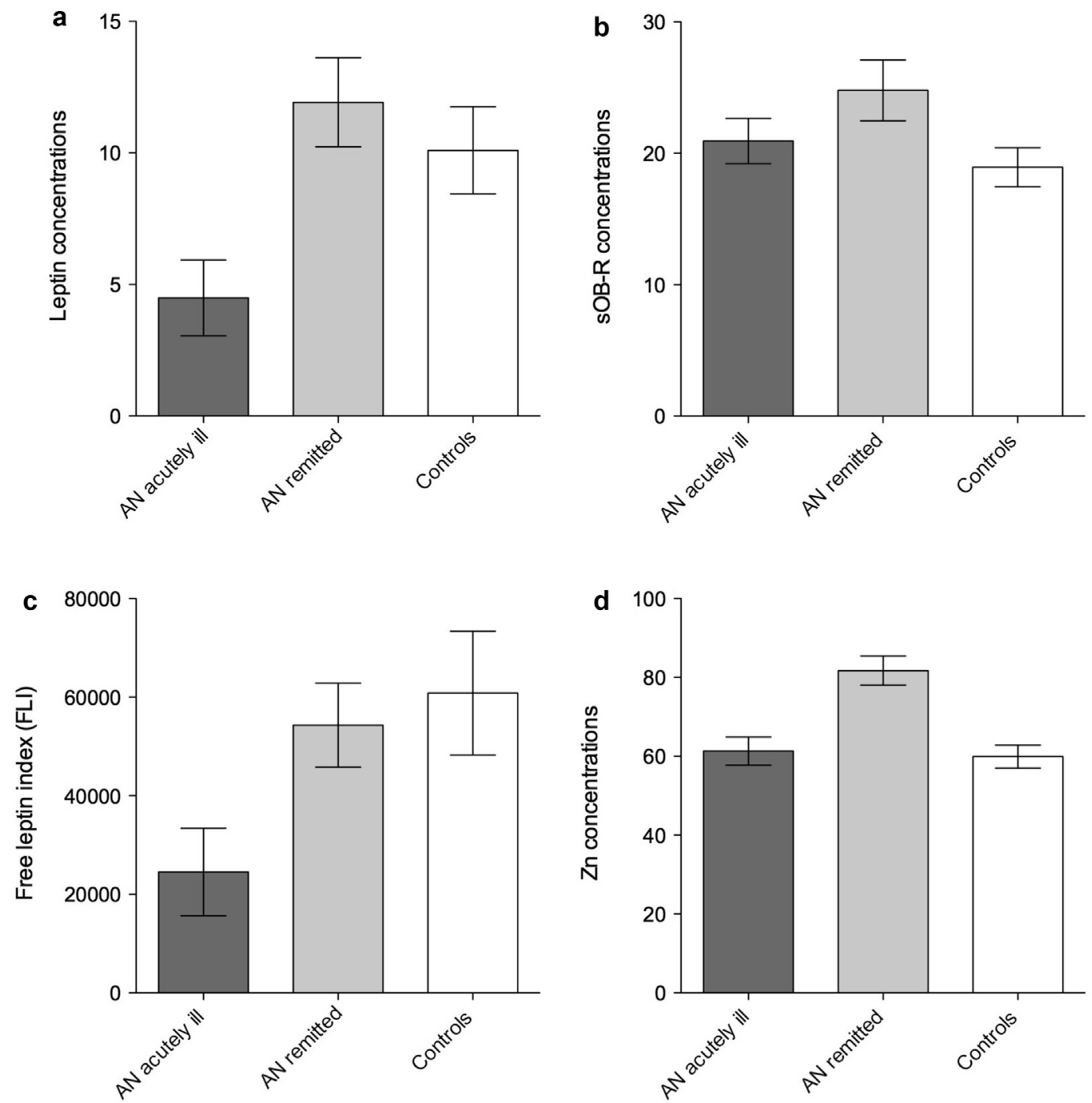

Fig. 1. Serum concentrations obtained in adolescents and young adults of (a) leptin (ng/ml), (b) the soluble leptin receptor (sOB-R, ng/ml), (c) free leptin index (FLI) and (d) zinc ( $\mathrm{Zn}, \mu \mathrm{g} / \mathrm{dl})$ with mean and SD for acutely ill $(n=14)$ and recovered patients $(n=15)$ with anorexia nervosa $(\mathrm{AN})$ and for healthy controls $(n=19)$.

\section{Dimensional analysis}

\section{Controls}

Serum $\mathrm{Zn}$ concentrations were not correlated with serum leptin $\left(r_{\mathrm{xy}}=-0.114 ; p>0.05\right)$, sOB-R $\left(r_{\mathrm{xy}}=\right.$ $0.091 ; p>0.05)$ or FLI $\left(r_{\mathrm{xy}}=-0.173 ; p>0.05\right)$.

\section{AN acutely ill}

$\mathrm{Zn}$ concentrations were not correlated with serum leptin $\left(r_{\mathrm{xy}}=0.253 ; p>0.05\right)$, sOB-R $\quad\left(r_{\mathrm{xy}}=-0.006\right.$; $p>0.05)$ or FLI $\left(r_{\mathrm{xy}}=0.229 ; p>0.05\right)$.

\section{AN remitted}

There were no correlations between serum $\mathrm{Zn}$ concentrations and serum leptin $\left(r_{\mathrm{xy}}=0.200 ; p>0.05\right)$, sOB-R $\left(r_{\mathrm{xy}}=-0.158 ; p>0.05\right)$ or FLI $\left(r_{\mathrm{xy}}=0.342\right.$; $p>0.05)$.
Post-hoc power analysis (for a significance level [alpha] of 0.05, two-tailed)

In order to estimate sample sizes for future large-scale studies, we calculated the power of the present study after completion.

Leptin

The experiment had a power of 0.60 to detect the smallest average difference in serum leptin concentrations $(5.21 \mathrm{ng} / \mathrm{ml})$ between pairs of controls $(n=15)$ and acutely ill patients $(n=14)$; the difference between controls and acutely ill patients was found to be $5.56 \mathrm{ng} / \mathrm{ml}$. We also estimated the statistical power with respect to the limitations of the intra- and interassay variance. To detect a difference between means of $3.40 \mathrm{ng} / \mathrm{ml}$ [a difference calculated for a mean in the control group of 
$8.84 \mathrm{ng} / \mathrm{ml}$ (actual mean value of $10.10 \mathrm{ng} / \mathrm{ml}-12.5 \%$ ) and a mean of $5.80 \mathrm{ng} / \mathrm{ml}$ for acutely ill patients (actual mean value of $4.53 \mathrm{ng} / \mathrm{ml}+12.5 \%)$ ] an adjusted power of 0.30 was calculated post-hoc. Future studies should take such limitations into account with respect to the used assay. When comparing remitted patients and controls, a power of 0.85 was calculated, detecting a difference between means of $7.46 \mathrm{ng} / \mathrm{ml}$ (the found difference was $7.39 \mathrm{ng} / \mathrm{ml}$ ). For the comparison of remitted and acutely ill patients, a power of 0.10 was calculated to detect a difference between means of $1.67 \mathrm{ng} / \mathrm{ml}$ (the found difference was $1.83 \mathrm{ng} / \mathrm{ml}$ ). Consequently, the present study had good power to detect differences in the means between controls and remitted patients, and only moderate power to detect differences between controls and acutely ill patients. However, the present study was underpowered in regard to the comparison of remitted patients and acutely ill patients.

FLI

In regard to FLI, the study had a power of 0.60 to detect a smallest average difference between pairs of $36.4 \times 10^{3}$ between controls and acutely ill patients (the difference found was $36.3 \times 10^{3}$ ). A power of 0.6 was also calculated to detect a smallest difference between pairs of $28.7 \times 10^{3}$ (the difference was $30.0 \times 10^{3}$ ) between remitted and acutely ill patients. For the comparison between remitted patients and controls, a power of 0.10 was calculated to detect a difference between means of $10.2 \times 10^{3}$ (but the difference was discovered to be $6.5 \times$ $10^{3}$ ). With this in mind, with respect to FLI, the present study had moderate power to detect significant differences in means between controls and acutely ill patients, as well as between acutely ill and remitted patients. However, in regard to the FLI comparison between remitted patients and controls, the present study was underpowered.

sOB-R

The study had a power of 0.50 to detect a smallest difference between means of control and remitted subjects of $5.80 \mathrm{ng} / \mathrm{ml}$ (the difference found was $5.85 \mathrm{ng} / \mathrm{ml}$ ). When comparing acutely ill and remitted patients, a power of 0.2 was calculated to detect a difference between pairs of $3.54 \mathrm{ng} / \mathrm{ml}$ (the difference found was $3.49 \mathrm{ng} / \mathrm{ml}$ ). For the comparison of acutely ill patients and controls, a power of 0.20 was calculated to detect a difference between these groups of $2.71 \mathrm{ng} / \mathrm{ml}$ (the difference found was $2.36 \mathrm{ng} / \mathrm{nl}$ ). As a consequence, the present study only had low moderate power to detect differences between controls and remitted patients, but was underpowered in finding differences between acutely ill and remitted patients, as well as acutely ill patients and controls.

\section{Discussion}

Along with data from previous research, the main results of the present work are:

1. Serum leptin levels and FLI, as well as serum $\mathrm{Zn}$ concentrations - mainly due to dietary preferences as regards $\mathrm{Ca}^{2+}$ and phosphorus containing foods (12) - were higher in remitted AN subjects compared with acutely ill patients.

2. Remitted patients showed significantly higher concentrations of the sOB-R but no difference in FLI when compared with healthy controls (while remitted patients were shown to have higher serum Zn concentrations).

3. Serum leptin levels and FLI were lower in acutely ill patients compared with controls, who displayed no differences in serum $\mathrm{Zn}$ concentrations. Additionally, serum $\mathrm{Zn}$ concentrations were not correlated with serum leptin, sOB-R or FLI concentrations in any of the three investigated subgroups (acutely ill patients, remitted patients and controls).

The present data are in line with previous research on the leptin state in AN showing lowered leptin concentrations in acutely ill patients with $\mathrm{AN}$, and that weight gain is associated with increased leptin levels or even hyperleptinaemia (22). However, the association between the stage and state of AN (i.e. acutely ill vs. remitted) in humans and changed serum leptin levels, FLI and $\mathrm{Zn}$ concentrations is not clear, particularly with respect to animal data obtained in rats suggesting that leptin expression may be directly affected by $\mathrm{Zn}$ (8). The data of the present investigation do not entirely support an association between serum $\mathrm{Zn}$ concentrations and different indices of the leptin axis, in particular because there were no significant correlations between serum $\mathrm{Zn}$ and leptin, sOB-R and FLI in any subgroup. In our study, remitted patients showed elevated serum leptin levels; because of this, FLI and $\mathrm{Zn}$ concentrations might be considered indicative of such a relationship, with respect to the stage of illness in younger patient populations.

However, the data provided by the present study must be considered preliminary, in particular because differences in serum $\mathrm{Zn}$ concentrations are likely to depend on reported food preferences (12). In addition, research proposing decreased food intake, rather than $\mathrm{Zn}$ deficiency itself, being associated with changes in plasma leptin availability in $\mathrm{Zn}$-deficient rats must be mentioned here $(9,10)$. Accordingly, these findings assume that low serum leptin concentrations, hypometabolism and diminished activity levels are more likely the result of anorexia per se than of $\mathrm{Zn}$ deficiency alone $(9,10)$. Notably, in our study, remitted patients showed higher sOB-R and $\mathrm{Zn}$ concentrations when compared with healthy controls, 
but there was no difference in FLI. Moreover, there was no difference in sOB-R concentrations observed between acutely ill and remitted patients with AN. Following this, more studies with larger samples are warranted in order to further investigate if changes in leptin expression are associated with differences in serum $\mathrm{Zn}$ status in patients with AN.

Unambiguous clinical conclusions cannot be drawn from the present study. However, if the finding that remitted patients with AN showed increased serum $\mathrm{Zn}$, FLI and leptin concentrations could be replicated in future large-scale studies, one could speculate that leptin expression is associated with altered serum $\mathrm{Zn}$ status in remitted patients; this would somewhat align with the aforementioned animal data (8). One could speculate that changed leptin expression in response to normalised or even elevated $\mathrm{Zn}$ concentrations in remitted patients, which is likely to be influenced by dietary factors (12), might reflect an adaptive mechanism with respect to the state of the illness, possibly in order to prevent relapse. However, such assumptions remain speculative at this stage. Randomised double-blind placebo-controlled trials with $\mathrm{Zn}$ supplementation and determination of serum leptin, sOB-R concentrations and FLI, also involving longitudinal follow-up assessments of the outlined parameters and clinical symptoms, would be necessary in order to address this question.

The present study is subject to limitations. In regard to the noted significant differences between groups, only the reported difference in leptin concentrations between remitted and acutely ill patients had insufficient statistical power; on the other hand, moderate power was calculated for the group differences between control subjects and acutely ill patients (leptin, FLI), as well as low to moderate power for remitted patients versus controls (sOB-R) and remitted versus acutely ill patients (FLI). Apart from the limited sample size (12), it must also be noted that within the group of acutely ill patients, blood samples were obtained at different BMI stages. To overcome this limitation, one would need a sample of patients with nearly equal BMIs upon admission, which is difficult to coordinate as patients generally present in different stages of the illness (and due to this, they display different BMI values upon admission) upon entry to clinical departments and subsequent inpatient treatment. In addition, no data on body fat and energy intake, in particular as regards the total quantity of food intake, were obtained. These aspects should be assessed in future studies, and the present data need to be replicated in larger samples.

In summary, the present study investigated the relationship between serum $\mathrm{Zn}$ concentrations and parameters of the leptin axis (sOB-R, FLI) in adolescent and young adult humans with AN. However, the relationship between the leptin axis and $\mathrm{Zn}$ concentrations remains unclear, in particular due to limited statistical power; some of the comparisons investigated only higher leptin concentrations in remitted patients compared with acutely ill patients, which parallel the higher serum $\mathrm{Zn}$ concentrations in remitted versus acutely ill patients. Because recent research has indicated that elevated serum $\mathrm{Zn}$ concentrations in remitted patients were likely due to dietary preferences (12), the relationship between changes in the leptin axis, as well as in serum $\mathrm{Zn}$ levels, should be further elucidated, in particular with respect to the stage of the illness. Altered concentrations of $\mathrm{Zn}$, leptin and FLI in remitted AN patients compared with acutely ill patients, with respect to healthy controls, need to be replicated using larger sample sizes. The present study provides an estimate for recommended sample sizes in regard to this type of future large-scale research.

\section{Conflict of interest and funding}

FDZ was the recipient of an unrestricted award donated by the American Psychiatric Association (APA), the American Psychiatric Institute for Research and Education (APIRE) and AstraZeneca (Young Minds in Psychiatry Award). He has also received research support from the German Federal Ministry for Economics and Technology, the German Society for Social Pediatrics and Adolescent Medicine, the Paul and Ursula Klein Foundation, the Dr. August Scheidel Foundation, and a travel stipend donated by the GlaxoSmithKline Foundation. $\mathrm{He}$ is the recipient of an unrestricted educational grant, travel support and speaker honoraria by Shire Pharmaceuticals, Germany. In addition, he has received support from the Raine Foundation for Medical Research (Raine Visiting Professorship). FP is a member of the advisory boards of Lilly, Janssen Cilag, AstraZeneca and Novartis. LW has received research funding from the Danone Institute related to this study. The other authors have nothing to disclose.

\section{Acknowledgements}

This study was funded by the Danone Institute (Institut Danone, Ernährung für Gesundheit e.V.) through a grant to L. Wockel.

\section{References}

1. Ahima RS, Prabakaran D, Mantzoros C, Qu D, Lowell B, Maratos-Flier E, et al. Role of leptin in the neuroendocrine response to fasting. Nature 1996; 382: 250-2.

2. Hebebrand J, Blum WF, Barth N, Coners H, Englaro P, Juul A, et al. Leptin levels in patients with anorexia nervosa are reduced in the acute stage and elevated upon short-term weight restoration. Mol Psychiatry 1997; 2: 330-4.

3. Holtkamp K, Mika C, Grzella I, Heer M, Pak H, Hebebrand J, et al. Reproductive function during weight gain in anorexia nervosa. Leptin represents a metabolic gate to gonadotropin secretion. J Neural Transm 2003; 110: 427-35.

4. Shay NF, Mangian HF. Neurobiology of zinc-influenced eating behavior. J Nutr 2000; 130: 1493S-9S. 
5. Mantzoros CS, Prasad AS, Beck FW, Grabowski S, Kaplan J, Adair C, et al. Zinc may regulate serum leptin concentrations in humans. J Am Coll Nutr 1998; 17: 270-5.

6. Ott ES, Shay NF. Zinc deficiency reduces leptin gene expression and leptin secretion in rat adipocytes. Exp Biol Med (Maywood) 2001; 226: 841-6.

7. Mangian HF, Lee RG, Paul GL, Emmert JL, Shay NF. Zinc deficiency supresses plasma leptin concentrations in rats. J Nutr Biochem 1998; 9: 47-51.

8. Kwun IS, Cho YE, Lomeda RA, Kwon ST, Kim Y, Beattie JH. Marginal zinc deficiency in rats decreases leptin expression independently of food intake and corticotrophin-releasing hormone in relation to food intake. Br J Nutr 2007; 98: 485-9.

9. Mocchegiani E, Bulian D, Santarelli L, Tibaldi A, Muzzioli M, Lesnikov V, et al. The zinc pool is involved in the immunereconstituting effect of melatonin in pinealectomized mice. J Pharmacol Exp Ther 1996; 277: 1200-8.

10. Gaetke LM, Frederich RC, Oz HS, McClain CJ. Decreased food intake rather than zinc deficiency is associated with changes in plasma leptin, metabolic rate, and activity levels in zinc deficient rats (small star, filled). J Nutr Biochem 2002; 13: 237-44.

11. Kratzsch J, Lammert A, Bottner A, Seidel B, Mueller G, Thiery $\mathrm{J}$, et al. Circulating soluble leptin receptor and free leptin index during childhood, puberty, and adolescence. J Clin Endocrinol Metab 2002; 87: 4587-94.

12. Zepf FD, Sungurtekin I, Glass F, Elstrodt L, Peetz D, Hintereder G, et al. Differences in serum $\mathrm{Zn}$ levels in acutely ill and recovered adolescents and young adults with anorexia nervosa - a pilot study. Eur Eat Disord Rev 2011; DOI: 10.1002/ erv.1164. [Epub ahead of print]

13. Fichter M, Quadflieg N. The structured interview for anorexic and bulimic disorders for DSM-IV and ICD-10 (SIAB-EX): reliability and validity. Eur Psychiatry 2001; 16: 38-48.

14. Fichter MM, Herpertz S, Quadflieg N, Herpertz-Dahlmann B. Structured interview for anorexic and bulimic disorders for DSM-IV and ICD-10: updated (third) revision. Int J Eat Disord 1998; 24: 227-49.
15. Paul T, Fichter, M., Quadflieg, N. Strukturiertes Interview für Anorektische und Bulimische Eßstörungen (SIAB). Fragebogen (SIAB-S) und Interview (SIAB-EX) nach DSM-IV und ICD-10. Göttingen: Hogrefe; 1999.

16. Paul T, Thiel, A. Eating Disorder Inventory-2 (EDI-2), German Version. Göttingen: Hogrefe; 2004.

17. Fallah S, Sani FV, Firoozrai M. Effect of contraceptive pill on the selenium and zinc status of healthy subjects. Contraception 2009; 80: 40-3.

18. Akhter S, Shamsuzzaman AK, Siddiqui NI, Banerjee M, Deb $\mathrm{K}$, Hossain MZ. Serum zinc status of rural women taking combined OC. Mymensingh Med J 2005; 14: 128-32.

19. Kratzsch J, Berthold A, Lammert A, Reuter W, Keller E, Kiess W. A rapid, quantitative immunofunctional assay for measuring human leptin. Horm Res 2002; 57: 127-32.

20. Liu C, Liu XJ, Barry G, Ling N, Maki RA, De Souza EB. Expression and characterization of a putative high affinity human soluble leptin receptor. Endocrinology 1997; 138: 3548-54.

21. Holm S. A simple sequentially rejective multiple test procedure. Scand J Statist 1979; 6: 65-70.

22. Hebebrand J, Muller TD, Holtkamp K, Herpertz-Dahlmann B. The role of leptin in anorexia nervosa: clinical implications. Mol Psychiatry 2007; 12: 23-35.

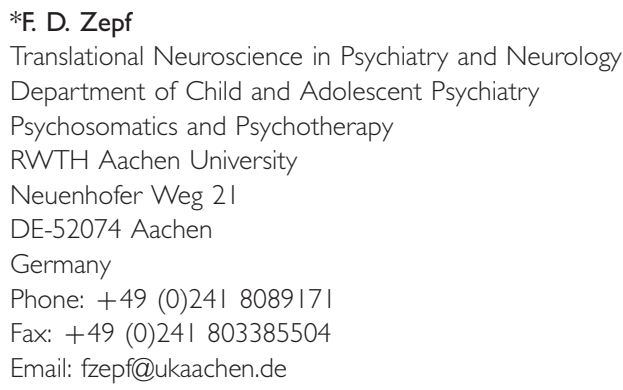

